Revista de Psicología Vol. 29 (2), 2011 (ISSN 0254-9247)

\title{
Cross-cultural assessment of emotions: The expression of anger
}

\author{
Manolete S. Moscoso ${ }^{1}$ and Charles D. Spielberger ${ }^{2}$ \\ University of South Florida, Tampa, USA
}

The purpose of this article is to focus on unique issues that are encountered in the crosscultural adaptation of measures of emotions. We take into consideration the cross-cultural equivalence of the concept of emotion, and how cultural differences influence the meaning of words that are utilized to describe these concepts. The critical need to take the state-trait distinction into account in adapting measures of emotional states and personality traits is then discussed. The effects of language and culture in adapting measures of the experience, expression, and control of anger in Latin-America are also reviewed. The construction of the Latin American Multicultural State-Trait Anger Expression Inventory is described.

Keywords: Anger expression, state-trait, cross-cultural adaptation, emotions.

\section{Medición transcultural de las emociones: la expresion de la ira}

Se presenta un análisis de las dificultades encontradas en el proceso de adaptación transcultural de pruebas de medición de las emociones. Se toma en consideración la equivalencia transcultural del concepto de emoción, y cómo las diferencias culturales tienen una gran influencia en el significado de las palabras a ser usadas para definir y describir las emociones y su medición. Se discute la importancia y necesidad de considerar el concepto de estado-rasgo en el proceso de adaptación de pruebas psicológicas que evalúan los estados emocionales. Se examina los efectos de la lengua y cultura en la adaptación de pruebas que evalúen la experiencia, expresión y control de la ira en Latinoamérica. Finalmente, se describe la construcción del Inventario Multicultural Latinoamericano de la Expresión de la Ira, Estado-Rasgo.

Palabras clave: expresión de la ira, estado-rasgo, adaptación transcultural, emociones.

$1 \quad$ Ph. D. in Psychology. University of South Florida/Health Schools of Medicine, Public Health \& Nursing. Contacto: 1978 Roseate Lane, Sanibel, FL 33957, USA; mmoscoso@health.usf.edu

2 Ph.D. in Psychology. Center for Research in Behavioral Medicine and Health Psychology. Contacto: 4202 East Fowler Avenue, Tampa, FL 33620, USA; spielber@usf.edu 

The International Test Commission Guidelines (ITC) provides excellent recommendations of methods and procedures for the crosscultural adaptation of educational and psychological tests. Following these guidelines is essential in adapting measures of achievement and aptitude to facilitate comparison of the relative performance of individuals from different languages and cultures. While the ITC Guidelines are applicable to adapting all types of psychological tests, personality and emotional states measures are quite different from aptitudes and abilities (Lievens, Harris, Van Keer \& Bisqueret, 2003). Emotional states and the behaviors that comprise personality traits are more subjective and less clearly defined than aptitudes, abilities, and achievement. Moreover, as Anastasi (1988, p. 532) has observed: "Even more than ability tests, personality tests can be expected to show large subcultural as well as cultural differences".

Differences in the interpretation of test instructions also contribute to problems in the cross-cultural adaptation of measures of emotions and personality. For example, Marsella and Leong (1995) observed that persons from non-Western cultures may be uncomfortable in giving true or false responses to the items of the Minnesota Multiphasic Personality Inventory (MMPI) because persons from collectivist cultures typically place greater emphasis on situational factors that influence their feelings and behavior. To illustrate this point, Marsella and Leong (1995, p. 208) quote a Filipino respondent to the MMPI who clearly expressed this concern: "Sir, sometimes true and sometimes false. I cannot tell you true or false all the time". Understanding such differences in the reactions to test instructions of respondents from different cultures requires knowledge of the special conditions and circumstances that are characteristic of a particular culture (Moscoso, 1997).

Construct equivalence is an essential requirement in the cross-cultural adaptation of all types of tests (Hambleton, 2000). In adapting measures of personality and emotions, special attention must also be given to the 
state-trait distinction (Cattell, 1966; Cattell \& Scheier, 1960; Cohen, Swerdlik \& Smith, 1992; Lonner, 1990), and to item intensity-specificity. In assessing individual differences, the relative frequency of occurrence of emotional states must also be evaluated (Spielberger, 1988).

The non-equivalence of constructs in different languages and cultures is perhaps the most serious source of error in adapting measures of personality and emotion (Moscoso, 1998). Cross-cultural equivalence is especially difficult to obtain with measures of emotions and personality because there is, as yet, relatively little agreement in regard to the criteria for defining the fundamental personality dimensions (Cohen et al., 1992; Cronbach, 1990). For example, there is only limited coherence between measures of the clinical syndromes on which MMPI scale scores are based and the personality dimensions assessed by the MMPI. Recognition of this shortcoming has stimulated the development of the MMPI-2 Content Scales for assessing anxiety, fear, depression and anger (Butcher, Graham, Williams \& Ben-Porath, 1989).

\section{Measuring personality traits and emotional states}

Definitions of personality vary from comprehensive accounts of behavior in all of its complex details to specific descriptions of individual personality traits (Guthrie \& Lonner, 1986). Anastasi (1988) emphasizes the importance of defining personality in terms of meaningful trait concepts that describe categories into which behavior must be classified if it is to be accurately measured. Consistent with Anastasi's emphasis on fundamental traits, Cohen et al. (1992) define personality as "an individual's unique constellation of psychological states and traits" (p. 401). Anxiety, anger and depression are examples of meaningful states and traits that are uniquely related to personality (Moscoso \& Spielberger, 1999a; Spielberger, Reheiser \& Sydeman, 1995).

The cross-cultural equivalence of anxiety and anger as emotional states and personality traits is facilitated by the fact that these fundamental emotions appear to be universal products of evolution. In 
his classic book, Expressions of Emotions in Man and Animals, Darwin (1872) concluded that fear and rage are intense emotions that can be identified by facial expressions, not only in humans, but also in many animal species. Consistent with these research findings, Dimberg (1998) observed that distinctive facial reactions are manifested after very brief exposure to fear and anger related relevant stimuli, such as snakes and angry faces, indicating that the perception of threatening stimuli can instantaneously evoke specific emotions.

The words used in different languages to describe emotional states and personality traits generally have a wide range of connotations (Rogler, 1999). Even within a particular language, the same word may have a variety of meanings in different subcultures (Moscoso, 2001). Therefore, differences between and within cultures, in the meaning of the words used to describe emotional states and personality traits, are especially problematic in the cross-cultural adaptation of measures of these constructs (Moscoso, 1999; Spielberger \& Moscoso, 1995). The following are examples of subcultural differences in the meaning of Spanish words (Cabrera, 1998): In Caribbean countries guagua means bus, but this same word refers to a baby or child in Chile, Colombia and Peru. Verraco is a pig in Cuba, but has the connotation in Colombia of a person who is tough. In Cuba, bicho refers to an insect, but describes a penis in Puerto Rico. In Spain, the verb coger has the innocuous meaning to take or to seize, but means having sex in Mexico and Venezuela.

These examples clearly indicate that the successful adaptation of self-report measures of emotional states and personality traits requires the careful selection of idioms that have essentially the same meaning in both the original (source) and second (target) languages. However, ensuring accurate representation of the psychological concepts that are assessed is often difficult because languages differ in the connotations of words used to describe the feelings and cognitions associated with different emotional states and personality traits (Spielberger, Moscoso \& Brunner, 2005). Moreover, as noted by Wierzbicka (1994, p. 135) “... the set of emotion terms available in any given language is unique and reflects a culture's unique perspective on people's ways of feeling" (p. 135). 
Self-report measures of anxiety, anger and depression cannot be simply translated and back-translated, but must be adapted for crosscultural research (Moscoso, 1998). The process of back translation is traditionally used to facilitate adapting educational and psychological tests from one language into another language (Brislin, 1986). In the back translation of test items, from the target language into the original language, the literal translation of words is emphasized. However, the back translation of an original scale item is often less adequate than constructing a new item based on an equivalent cross-cultural conceptual definition of the emotional state or personality dimension that is being measured (Spielberger \& Diaz-Guerrero, 1982). This is especially true in adapting idiomatic expressions.

Translating of key words and idiomatic expressions is especially difficult, and may require frequent consultations with language experts. From the standpoint of the exactness of the translation, it is recommended that items be grouped into three categories: a) Items with key words whose translations closely fit the meaning of the word in the source language, b) items with key words for which it is difficult to find corresponding items in the target language, and c) items with a linguistic form that cannot be translated from the source language to the target language without changing the grammatical construction. A number of cycles of translation and back translation may be required before an adequate adaptation can be developed for the latter type of item (Moscoso \& Spielberger, 1999a).

In adapting measures of emotional states and personality traits, the key word for an item in the source language may have several different translations that are equally acceptable in the target language. Different key words in two or more items in the source language may also be represented by a single word in the target language. Where the literal translation of a scale item is not possible, it is important to retain the essential meaning of the original item by selecting a synonym of the key word that reflects its basic meaning in the target language.

When adapting idiomatic expressions, special care must be taken to translate the feeling connotation of the idiom, rather than translating the literal meaning of the individual words (Guthrie \& Lonner, 
1986). Identifying comparable idiomatic expressions in the language into which a scale is being translated is preferable to the literal translation of the original idiom. Consequently, in translating and adapting idioms, the cross-cultural equivalence of the theoretical concepts that are being measured is essential. Given the difficulties that are likely to be encountered in translating key words and idiomatic expressions, a substantially larger pool of items than will be eventually needed should be constructed in order to capture the full meaning of the construct that is being measured. Statistical and validation procedures can then be used to determine which items have the best internal consistency as measures of the specified construct (McPhail, 2007).

\section{Cross-cultural assessment of the experience, expression and control of anger}

Over the last quarter century, interest in measuring the experience, expression and control of anger has been stimulated by evidence that anger, hostility and aggression were associated with hypertension and cardiovascular disease (Spielberger \& Moscoso, 1995; Williams, Barefoot \& Shekelle, 1985). While definitions of anger-related constructs are often inconsistent and ambiguous, the experience and expression of anger are typically encompassed in definitions of hostility and aggression. Clearly, anger is the most fundamental of these overlapping constructs.

On the basis of a careful review of the research literature on anger, hostility and aggression, the following definitions of these constructs were proposed by Spielberger and Moscoso (1995). Anger usually refers to an emotional state that consists of feelings that vary in intensity, from mild irritation or annoyance to intense fury and rage. Although hostility involves angry feelings, this concept has the connotation of a complex set of attitudes that motivate aggressive behaviors directed toward destroying objects or injuring other people. The concept of aggression generally implies destructive or punitive behavior directed towards other persons or objects. 
The physiological and behavioral manifestations of anger, hostility, and aggression have been investigated in numerous studies, but until recently, angry feelings have been largely ignored in psychological research. Consequently, psychometric measures of anger, hostility, and aggression generally do not distinguish between feeling angry and the expression of anger and hostility in aggressive behavior. Most measures of anger-related constructs also fail to take the state-trait distinction into account, and confound the experience and expression of anger with situational determinants of angry behavior (Moscoso, 2001). A coherent theoretical framework that recognizes the difference between anger, hostility, and aggression as psychological constructs, and that distinguishes between anger as an emotional state and individual differences in the experience, expression, and control of anger as personality traits, is essential for guiding the construction and cross-cultural adaptation of anger measures (Moscoso \& Spielberger, 1999b).

\section{Measuring state and trait anger}

The State-Trait Anger Expression Inventory (STAXI) was developed by Spielberger and his colleagues to measure the experience, expression and control of anger (Spielberger, Krasner \& Solomon, 1988). The State-Trait Anger Scale (STAS) was constructed to assess the intensity of anger as an emotional state and individual differences in anger proneness as a personality trait (Spielberger, 1983). S-Anger was defined as "an emotional state marked by subjective feelings that vary in intensity from mild annoyance or irritation to intense fury or rage, which is generally accompanied by muscular tension and arousal of the autonomic nervous system" (Spielberger, 1988, p. 1). Trait anger refers to individual differences in the disposition to experience angry feelings (Spielberger, 1983). The STAS T-Anger Scale evaluates how frequently $S$-Anger is experienced. 


\section{Measuring the expression and control of anger}

Recognition of the importance of distinguishing between the experience and expression of anger stimulated the development of the Anger Expression (AX) Scale (Spielberger, 1988). The AX Scale assesses how often anger is suppressed (anger-in) or expressed in aggressive behavior (anger-out). The instructions for responding to the AX Scale differ markedly from the traditional trait instructions for the STAS T-Anger Scale. Rather than directing subjects to respond according to how they generally feel, they are instructed to report how often they react or behave in a particular manner when they feel "angry or furious" (e. g. "I say nasty things", "I boil inside, but don't show it") by rating themselves on the same 4-point frequency scale that is used with the T-Anger Scale.

The identification of anger control as an independent factor stimulated the construction of a scale to assess the control of angry feelings (Spielberger, 1988). The content of 3 of the 20 original AX Scale items (e. g. control my temper, keep my cool, calm down faster), which were included to assess intermediate levels of anger expression as an unidimensional bipolar scale, guided the generation of additional anger control items.

The last stage in the construction of the STAXI was stimulated by the research of psycholinguists, who identified English metaphors for anger, which called attention to the need to distinguish between two different mechanisms for controlling anger expression (Lakoff, 1987). The prototype of the anger metaphor was described as a hot liquid in a container, where blood was the hot liquid and the body was the container. The intensity of anger as an emotional state is considered analogous to the variations in the temperature of the hot liquid. The metaphor, boiling inside, has the connotation an intense level of suppressed anger; blowing off steam connotes the outward expression of angry feelings; keeping the lid on implies controlling intense anger by preventing the outward expression of aggressive behavior. Thus, Lakoff's (1987) anger metaphors suggested two quite different 
mechanisms for controlling anger: keeping angry feelings bottled up to prevent their expression, and reducing the intensity of suppressed anger by cooling down.

In the original STAXI scale, the content of all but 1 of the $8 \mathrm{AX} /$ Con items was related to controlling anger-out (e. g. "I control my temper"). Therefore, a number of new items were constructed to assess the control of anger-in by reducing the intensity of suppressed anger (Sydeman, 1995). The content of these items described efforts to calm down, cool off, or relax when a person feels angry or furious. Factor analyses of the responses of large samples of male and female adults to the anger-control items identified two anger control factors for both sexes: Anger/Control-In and Anger/Control-Out.

\section{Construction of the Latin American Multicultural State-Trait Anger Expression Inventory}

Spanish is spoken not only in Spain, but also in more than 20 countries in Central and South America and the Caribbean, and by more than 40 million native speakers of Spanish who reside in the United States. Although Spanish is the primary language in most of Latin America and for many Hispanic residents in the U.S., the indigenous cultures of these persons often have profound effects on the Spanish they speak, and on the development of personality characteristics that influence their behavior. Therefore, it is important to recognize the exceptionally complex social and cultural diversity of Hispanic populations, and that language differences between these groups may outweigh the similarities. Consequently, in adapting English measures of emotion and personality for use in Spanish-speaking cultures, care must be taken to ensure that the key words and idiomatic expressions used for assessing anger-related concepts have essentially the same meaning in different Hispanic cultural groups (Moscoso \& Nieto, 2003).

The STAXI-2 was adapted to measure the experience, expression and control of anger in culturally diverse populations in Latin America, 
and in Spanish-speaking subcultures in the United States (Moscoso, 2000; Moscoso \& Spielberger, 1999a). Toward achieving this goal, the Latin American Multicultural State-Trait Anger Expression Inventory (STAXI-LAM) was designed to measure essentially the same dimensions of anger that are assessed with the STAXI-2 (Spielberger, 1999). Scales and subscales were constructed to assess the following dimensions with the STAXI-LAM: a) State Anger, with subscales for assessing Feeling Angry and Feel Like Expressing Anger; b) Trait Anger, with subscales for measuring Angry Temperament and Angry Reaction; and c) trait scales for measuring four dimensions of anger expression and control: anger-in, anger-out, and the control of anger-in and anger-out (Moscoso \& Spielberger, 1999b).

Preliminary translations of the STAXI-2 items were constructed for the STAXI-LAM. These items were reviewed by 26 prominent Latin American psychologists, who were instructed to recommend modifications and corrections in conformance with linguistic descriptors of the experience, expression, and control of anger in their countries (Moscoso, 2000). Based on the consensus of these experts, the STAXI-LAM items were revised, and the 56-item revised scale was administered to 257 participants (179 females, 78 males) at the 25th Inter-American Congress of Psychology in San Juan, Puerto Rico. The sample included respondents from Caribbean countries (48\%), South America (32\%), Central America (16\%) and Spain (4\%), who ranged in age from 20 to 78 years (median age $=36$ years). All participants had completed training in psychology, or were currently enrolled in undergraduate or graduate psychology programs.

Factor analyses of responses to the 56 preliminary STAXI-LAM items confirmed the hypothesized structural properties of the inventory. The eight factors that were identified corresponded quite well with similar factors in the STAXI-2. These included $2 \mathrm{~S}$-Anger factors, $2 \mathrm{~T}$-Anger factors, and 4 anger expression and control factors (Moscoso \& Spielberger, 1999a). In separate factor analyses of the S-Anger items, two distinctive factors were identified for both males and females: Feeling angry and Feel like expressing anger. However, gender differences in the strength of the 
item loadings on these factors raised interesting questions in regard to how Latin American men and women may differ in the experience of anger. For females, the feeling angry factor accounted for $73 \%$ of the total variance, while this factor accounted for only $19 \%$ of the variance for males. In contrast, the feel like expressing anger factor accounted for $70 \%$ of the total variance of the males, but only $13 \%$ for females.

The factor analyses of the T-Anger STAXI-LAM items also identified separate Angry Temperament and Angry Reaction factors, providing strong evidence that the factor structure for this scale was similar to that of the STAXI-2. Factor analyses of the STAXI-LAM anger expression and control items identified the same four factors as in the STAXI-2. The items designed to assess anger-in and anger-out, and the control of anger-in and anger-out, had high loadings on the corresponding anger expression and control factors, which were similar for both sexes. The alpha coefficients for the STAXI-LAM State and Trait Anger scales and subscales, and the anger expression and anger control scales, were reasonably high, indicating that the internal consistency of these scales was satisfactory.

In summary, the results of the factor analyses of responses of the Latin American subjects to the STAXI-LAM items of the Latin American subjects identified 8 factors that were quite similar to those found for the STAXI-2. Separate factor analyses of the S-Anger and T-Anger items confirmed the identification of two related but distinctive S-Anger factors: feeling angry and feel like expressing anger, and two highly correlated but clearly different T-Anger factors, Angry Temperament and Angry Reaction. Factor analyses of the anger expression and control items also identified the same four factors that are found in the STAXI-2. Thus, the multidimensional factor structure of the STAXILAM for the Latin American respondents was remarkably similar to the factor structure of the English STAXI-2. 


\section{Summary and recommendations}

In adapting measures of emotional states and personality traits, the non-equivalence of psychological constructs in different cultures is a major source of error. Cross-cultural equivalence is especially problematic in adapting personality measures because agreement is lacking in regard to the criteria for defining the fundamental dimensions of personality. Therefore, the cross-cultural equivalence of the concepts that define the dimensions that are being measured is essential. Special attention must be given to distinguishing between emotional states that vary in intensity, and individual differences in personality traits that are relatively stable over time. In constructing items to measure emotional states and personality traits, it is also essential to take itemintensity specificity into account so that the full range of intensity of an emotional state can be assessed.

The cross-cultural equivalence of anxiety, anger and depression as psychological constructs is facilitated by the fact that these emotions appear to be universal products of evolution. Darwin observed that fear (anxiety) and rage (anger) are universal characteristics of both humans and animals. These emotions mediate and motivate fight-or-flight reactions that were recognized by Cannon as contributing to successful adaptation and survival. Both anxiety and anger vary in intensity as a function of how individuals react to stressful circumstances, and people differ in the intensity and frequency that they experience these fundamental emotions.

The words used in different languages to describe emotional states and personality traits are markedly influenced by cultural differences, which reflect the unique perspective of a particular culture in regard to the feelings associated with a particular emotion. In the cross-cultural adaptation of psychological tests, careful selection of words and/ or idioms that have essentially the same meaning in both the source and target languages is required to ensure accurate representation of the psychological constructs that are being assessed. In adapting measures of emotional states and personality traits, it is also important to 
consider cultural differences in the meaning of words for persons who speak the same language.

Traditionally, the process of adapting psychological scales has involved the back translation of items from the target language to the source language. While emphasizing the literal translation of each word, this approach gives relatively little consideration to the constructs that are being measured. Two major limitations of back translation are the difficulty of finding words in the target language with meaning equivalent to key words in the source language, and translating idiomatic expressions. For idiomatic expressions, it is essential to adapt the feeling connotation of the idiom in the source language rather than translating the literal meaning of each word. It is also highly desirable to identify idioms with comparable meaning in the source and target languages.

In the cross-cultural adaptation of anger measures, it is essential to have equivalent conceptual definitions in the source and target languages that distinguish between the experience of anger as an emotional state, and individual differences in the expression and control of anger as personality traits. The construction and development of the Latin American Multicultural State-Trait Anger Expression Inventory guided by definitions of state and trait anger and anger-expression and angercontrol as these constructs were conceptualized in the STAXI-2. Factor analyses of the items constructed for the STAXI-LAM identified eight factors that were quite similar to the factor structure of the STAXI-2. Thus, statistical analyses of the responses to the STAXI-LAM items verified that the components of anger assessed with this inventory are similar to the anger components assessed with the STAXI-2. Research on the STAXI-2 and the STAXI-LAM clearly indicates that anger as a psychological construct can be meaningfully defined as an emotional state that varies in intensity and as a complex personality trait with major components that can be measured empirically. 


\section{References}

Anastasi, A. (1988). Psychological testing (6th ed.). New York: Macmillan. Brislin, R. W. (1986). The wording and translation of research instruments. In W. J. Lonner \& J. W. Berry (Eds.), Field methods in cross-cultural research (Vol. 8, pp. 137-164). Beverly Hills, CA: Sage.

Butcher, J. N., Graham, J. R., Williams, C. L., \& Ben-Porath, Y. S. (1989). Development and use of the MMPI-2 Content Scales. Minneapolis, MN: University of Minnesota Press.

Cabrera, C. (1998, August 14). Tricky translations: When speaking Spanish, what's acceptable in some countries could get you in trouble in others. The Tampa Tribune, Baylife Section, pp. 1-2.

Cattell, R. B. (1966). Patterns of change: Measurements in relation to state-dimension, trait change, ability, and process concepts. In R. B. Cattell (Ed.), Handbook of multivariate experimental psychology (pp. 288-329). Chicago, IL: Rand McNally.

Cattell, R. B. \& Scheier, I. H. (1960). Stimuli related to stress, neuroticism, excitation, and anxiety response patterns. Journal of Abnormal and Social Psychology, 60, 195-204.

Cohen, R. J., Swerdlik, M. E., \& Smith, D. K. (1992). Psychological testing and assessment: An introduction to tests and measurements (2nd. ed.). Mountain View, CA: Mayfield.

Cronbach, L. J. (1990). Essentials of psychological testing (5th ed.). New York: Harper \& Row.

Darwin, C. (1965). Expression of emotions in man and animals. Chicago: University of Chicago Press. (Originally published in 1872).

Dimberg, U. (1998). Fear of snakes and facial reactions: A case of rapid emotional responding. Scandinavian Journal of Psychology, 39, 75-80.

Guthrie, G. M. \& Lonner, W. J. (1986). Assessment of personality and psychopathology. In W. J. Lonner \& J. W. Berry (Eds.), Field methods in cross-cultural research (Vol. 8, pp. 231-264). Beverly Hills, CA: Sage. 
Hambleton, R. K. (2000). Issues, designs, and technical guidelines for adapting tests in multiple languages and cultures. In R. K. Hambleton, P. F. Merenda \& C. D. Spielberger (Eds.), Adapting educational and psychological tests for cross-cultural assessment. Hillsdale, NJ: Lawrence Erlbaum.

Lakoff, G. (1987). Women, fire, and dangerous things: What categories reveal about the mind. Chicago: University of Chicago Press.

Lievens, F., Harris, M. M., Van Keer, E., \& Bisqueret, C. (2003). Predicting cross-cultural training performance: The validity of personality, cognitive ability, and dimensions measured by an assessment center and a behavioral description interview. Journal of Applied Psychology, 88, 476-489.

Lonner, W. J. (1990). An overview of cross-cultural testing and assessment. In R. W. Brislin (Ed.), Applied cross-cultural psychology (pp. 56-76). Newbury Park, CA: Sage.

McPhail, S. M. (2007). Alternative validation strategies: Developing new and leveraging existing validity evidence. San Francisco, CA: Wiley.

Marsella, A. J. \& Leong, F. T. (1995). Cross-cultural issues in personality and career assessment. Journal of Career Assessment, 3(2), 202-218.

Moscoso, M. S. (1997). Medición de la cólera y hostilidad: implicaciones en el tratamiento psicológico con pacientes VIH/SIDA. Revista Peruana de Psicología, 2(4), 39-64.

Moscoso, M. S. (1998). Estrés, salud y emociones: estudio de la ansiedad, cólera y hostilidad. Revista de Psicología de la Universidad Nacional Mayor de San Marcos, 3, 47-68.

Moscoso, M. S. (1999). Medición de la expresión de la cólera y hostilidad. Revista de Psicología de la Universidad Nacional Mayor de San Marcos, 4, 169-188.

Moscoso, M. S. (2000). Estructura factorial del Inventario Multicultural Latinoamericano de la Expresión de la Cólera y la Hostilidad. Revista Latinoamericana de Psicología, 32(2), 321-343. 
Moscoso, M. S. (2001). Estudio de la rabia y hostilidad: sus efectos en la salud. Revista Comportamiento de la Universidad Simón Bolivar, 6, 17-39.

Moscoso, M. S. (2007). La expresión y supresión de la cólera: sus efectos en la salud y su medición psicométrica en América Latina. Revista Psicológica Herediana, 2(2), 104-114.

Moscoso, M. S. \& Spielberger, C. D. (1999a). Evaluación de la experiencia, expresión y control de la cólera en Latinoamérica. Psicología Contemporánea, 6(1), 4-13.

Moscoso, M. S. \& Spielberger, C. D. (1999b). Measuring the experience, expression, and control of anger in Latin America: The Spanish multi-cultural State-Trait Anger Expression Inventory. Interamerican Journal of Psychology, 33(2), 29-48.

Rogler, L. H. (1999). Methodological sources of cultural insensitivity in mental health research. American Psychologist, 54(6), 424-433.

Spielberger, C. D. (1983). Manual for the State-Trait Anxiety Inventory (Rev. ed.). Palo Alto, CA: Consulting Psychologists Press.

Spielberger, C. D. (1988). State-Trait Anger Expression Inventory Manual. Odessa, FL: Psychological Assessment Resources.

Spielberger, C. D. (1999). State-Trait Anger Expression Inventory-2. Odessa, FL: Psychological Assessment Resources.

Spielberger, C. D. \& Díaz-Guerrero, R. (1982). Cross-cultural anxiety: An overview. In C. D. Spielberger \& R. Díaz-Guerrero (Eds.), Cross-cultural anxiety (Vol. 2). New York: Hemisphere/McGrawHill.

Spielberger, C. D., Krasner, S. S., \& Solomon, E. P. (1988). The experience, expression and control of anger. In M. P. Janisse (Ed.), Health psychology: Individual differences and stress (pp. 89-108). New York: Springer Verlag.

Spielberger, C. D. \& Moscoso, M. S. (1995). La expresión de cólera y hostilidad y sus consecuencias en el sistema cardiovascular. Psicología Contemporánea, 2(1), 32-43.

Spielberger, C. D., Moscoso, M. S., \& Brunner, T. M. (2005). Crosscultural assessment of emotional states and personality traits. In 
R. K. Hambleton, P. F. Merenda \& C. D. Spielberger (Eds.), Adapting educational and psychological tests for cross-cultural assessment (pp. 343-367). New Jersey: Lawrence Erlbaum.

Spielberger, C. D., Reheiser, E. C., \& Sydeman, S. J. (1995). Measuring the experience, expression, and control of anger. In $\mathrm{H}$. Kassinove (Ed.), Anger disorders: Definitions, diagnosis, and treatment. Washington, DC: Taylor \& Francis.

Sydeman, S. J. (1995). The control of suppressed anger (Unpublished master's thesis). University of South Florida, Tampa, USA.

Wierzbicka, A. (1994). Emotion, language, and cultural scripts. In S. E. Kitayama \& H. R. M. Markus (Eds.), Emotion and culture: Empirical studies of mutual influence (pp. 133-195). Washington, DC: American Psychological Association.

Williams, R. B., Barefoot, J. C., \& Shekelle, R. B. (1985). The health consequences of hostility. In M. A. Chesney \& R. A. Rosenman (Eds.), Anger and hostility in cardiovascular and behavioral disorders (pp. 173-185). New York: Hemisphere/McGraw-Hill.

Recibido: 24 de marzo, 2011 Aceptado: 18 de julio, 2011 